The soil of the plains is clayey, partly bare, and cracked into more or less regular hexagonal figures, partly covered by a turf of grass, mosses, and lichens resembling that at the last landing-place. The rock here, however, was not granite, but upright unfossiliferous schistose strata rich in crystals of sulphide of iron, and crossed at the extremity of the cape by thick quartz veins. Dr. Kjellman could not find here more than twenty-four species of phanerogamous plants, most of them distinguished by a disposition to form compact half-globular tufts. The lichen vegetation was also, according to Dr. Almquist, monotonous, though luxuriantly developed. It almost appeared as if the plants of the Chelyuskin peninsula had attempted to wander farther toward the north, but halted when they met the sea, at the very outermost point. For here were found within a very limited space nearly all the plants, both phanerogams and cryptogams, which the land had to offer, and many of them were sought for in vain farther up on the plains.

Animal life on land rivalled the higher plant life in poverty. Of birds there were seen only a number of Phalaropus, some species of Tringa, a Colymbus arcticus, a very numerous flock of Anser bernicla, a few eiders, and the remains of a snowy owl. In the neighbouring sea, which was almost free of ice, were seen a single walrus, two shoals of white whales and some few seals (Phoca hispida). It, too, was here evidently very poor in warmblooded animals. On the other hand the dredge brought up from the sea-bottom various large algx (Laminaria agardhi, \&\&.), and a large number of lower animals, among them very large specimens of Idothec entomon, an isopod, which also occurs in the Baltic and the large Swedish lakes, and is looked upon as an evidence that during the ice age they were connected with the Polar Sea. The algæ obtained were interesting as affording further proof of the incorrectness of the view which long prevailed, that the Siberian Polar Sea was quite devoid of the higher alga.

On August 20 the voyage was resumed, the course being set east by south, in the hope of falling in with a continuation of the new Siberian Islands. Drift-ice was soon met with, and by the morning of the $23 \mathrm{rd}$ it was found impossible to proceed further in that direction. An attempt was now made by sailing in a northerly and zorth-westerly direction to get out of the ice-field, and in about twenty-four hours the Vega was again in open water, and the same day land was sighted. The land was found to be the north-eastern extremity of the eastern Taimyr Peninsula, lying in about $76^{\circ} 30^{\prime} \mathrm{N}$. L., and about $113^{\circ} \mathrm{E}$. of Greenwich. The sea was completely free of ice for a distance of $15^{\prime}$ or $16^{\prime}$. Fine mountains 2,000 to 3,000 feet high were seen some distance inland. These, like the plains below, were free of snow to their highest summits. Some small glaciers were believed to be seen, but they ended at a height of about 800 to $\mathrm{s}, 000$ feet above the sea.

Animal life now began to be very abundant. Dr. Stuxberg had, while the vessel lay anchored to a floe in the drift-ice-field, brought up from a depth of 35 fathoms an unexpected variety of fine marine animal types, among them three specimens of a crinoid supported on a stalk, probably young individuals of Alecto eschrichtii, which also was found in innumerable fullgrown specimens, masses of asterids (for instance Solaster papposus, endeca, furcifer, Pteraster militaris, Asterophyton eucnemis), and of the otherwise exceedingly rare Molpadia borealis, a colossal pycnogonid of 180 millimetres diameter, \&c. Not less abundant was the lower animal life at a smaller depth though the forms were partly different. The animals occurring here were evidently pure Polar Sea types without any immigration whatever from southern seas, such as has doubtless taken place in the case of the fauna of Spitzbergen.

On August 24 land was sighted, which was found to be
Preobraschenski Island, near the mouth of the river Katanga. From this point to the mouth of the Lena the depth was only from 5 to 8 fathoms.

To judge from the experience of the voyage there is no more ice on the Siberian coast during the latter part of summer than in the White Sea during midsummer. Besides the ordinary observations of the temperature of the sea-water at the surface in connection with the common meteorological observations made six times in the twenty-four hours, the temperature and salinity of the water at difterent depths were determined two or three times a day. When the depth amounts to at least 30 metres the temperature at the bottom is found to vary between $-10^{\circ}$ and $-14^{\circ} \mathrm{C}$. The specific gravity of the water amounts there to $\mathrm{I}^{\circ} \mathrm{O}_{2} 6-\mathrm{I} \cdot 027$, the salinity being little less than that of the water of the Atlantic Ocean. On the surface the temperature is exceedingly variable:-At Dickson Harbour $+10^{\circ}$, a little south of Taimyr Sound $+54^{\circ}$, among the drift ice off that sound $+0.8^{\circ}$, off Taimyr Bay $+30^{\circ}$, at Cape Chelyuskin $+0^{\circ} 1^{\circ}$, off Katanga Bay $+40^{\circ}$, between Katanga and Lena $+12^{\circ}$ to $+5.8^{\circ}$. The specific gravity of the surface-water in a broad channel along the coast never exceeded I.023, in general only amounted to $\mathrm{I}^{\circ} \mathrm{OI}$ or under. The latter figure corresponds to a mixture of about one part sea water with two parts river water. This shows indisputably that a warm surface current of little salinity from the mouths of the Obi and the Yenissei runs first along the coast towards the north-east, and then under the influence of the rotation of the earth in an easterly direction. Other similar currents originate from the Katanga, Anabor, Olonek, Lena, Jana, Indigirka, and Kolyma, all which pour their waters, more or less heated during the hot summer of Siberia, into the Polar Sea and render it, during a short period of the year, almost free of ice.

On the night between August 27 and 28 the Vega parted from the Lena off the mouth of the River Lena. There is scarcely any hope now that the voyage will be completed before next summer. No doubt the Vega has got into a safe winter-harbour, and that during the detention of the expedition a rich harvest of scientific results will be gathered.

\section{THE FORMATION OF MOUNTAINS}

PROF. ALPHONSE FAVRE, of Geneva, has been making an interesting series of experiments to illustrate the formation of the great inequalities of the earth's surface by means of lateral thrust or crushing. These he describes and illustrates in a recent number of $L a$ Nature, to which we are indebted for the illustrations which accompany this article. Prof. Favre refers to the early experiments of Sir James Hall with various kinds of cloth, which he made to assume a variety of shapes by means of weights. He speaks of the various theories of the elevation of mountains, and especially of that of H. B. de Saussure, whose term refoulement seems to have meant much the same as that used by M. Favre, écrasement lateral.

The three systems, M. Favre says, which account for the origin of mountains by forces which push the great mineral masses from below upwards, from above downwards, or laterally, do not differ so much from each other as at first sight appears. Those geologists nho have admitted the system of elevations as the principal cause of modification of the surface of the globe, would probably enough admit the formation of depressions as a secondary modification; and so those who have accounted for these modifications mainly by depression, would probably enough also admit elevation as a secondary factor. Again, in the system of lateral crushing, there is a general depression of the surface of the earth, since there is a diminu- 
tion in the length of the radius of our globe, and yet there result elevations of the ground in the midst of this general depression.

The cause of lateral crushing, M. Favre goes on to say, is owing to the cooling of the earth. It is, in fact, very probable that our globe is at the stage when, according to Élie de Beaumont, "the mean annual cooling of the mass exceeds that of the surface, and exceeds it more and more." It must follow that the external strata of the globe, tending.always to rest on the internal parts, are wrinkled, folded, dislocated, depressed at certain points, and elevated at others.

"The experiments," M. Favre continues, "which I have made at the works of the Geneva Society for the manufacture of physical instruments, resemble much those of Sir James Hall; they differ notably, however, in two points:- -1 . The celebrated Scotchman caused the matter which he wished to compress to rest on a body

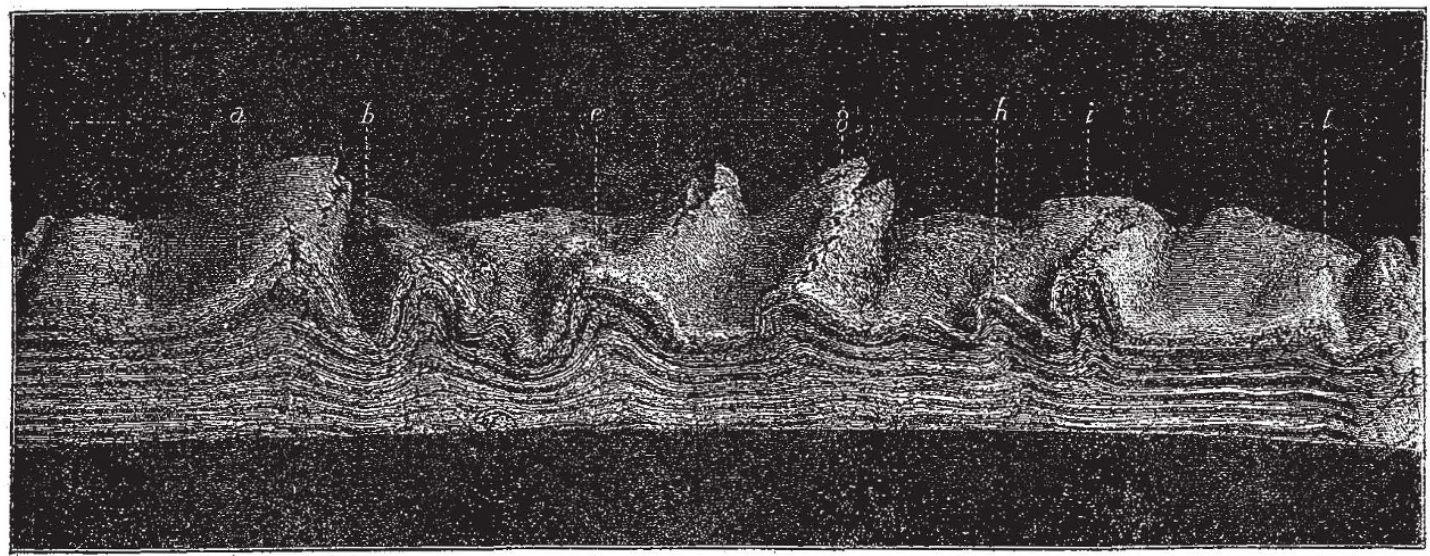

H.IG. I.

which itself could not be compressed, while I placed the layer of clay employed in these experiments on a sheet of caoutchouc, tightly stretched, to which I made it adhere as much as possible; then I allowed the caoutchouc to resume its original dimensions. By its con. traction the caoutchouc would act equally on all points of the lower part of the clay, and more or less on all the mass in the direction of the lateral thrust. 2. Hall compressed, by a weight, the upper surface of the body which he wished to wrinkle, which prevented any deformation, while by leaving that surface free, I have seen, during the experiment, forms appear similar to those of hills and mountains which may be observed in various countries."

"The arrangement of the apparatus is very simple. A sheet of india-rubber $16 \mathrm{~mm}$. in thickness, $12 \mathrm{~cm}$. broad, and $40 \mathrm{~cm}$. long, was stretched, in most of the experi ments, to a length of $60 \mathrm{~cm}$. This was covered with a.

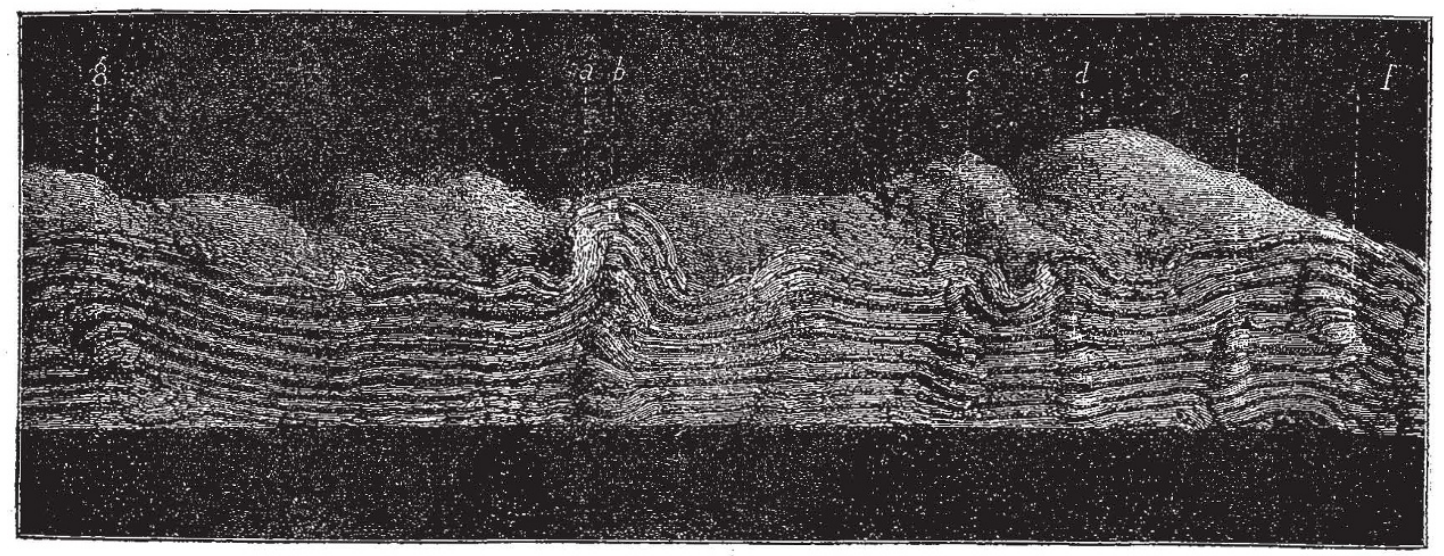

F:G. 2.

layer of potter's clay in a pasty condition, the thickness of which varied, according to the experiments, from 25 to $60 . \mathrm{mm}$. It will be seen from the dimensions indicated that pressure would diminish the length of the band of clay by one-third. This pressure has been exerted on certain mountains of Savoy. For example, the section which I have given ${ }^{1}$ of the mountains situated between the Pointe-Percée and the neighbourhood of Bonneville

\footnotetext{
$\therefore$ Bullet. Société Géologique de France, 1875 , t. iii. pl. xxii. A. Favre,
} Recherches Géologiques, Atlas, pl. ix. enables it to be seen that those folded and contorted strata which are shown between: Dessy and the Cal du Grand: Barnaud cover a length which is two-thirds of that which they had before compression. These mountains, then; have been subjected, like the potter's clay, to a compression indicated by the ratio of 60 to 40 . Contortions are not, perhaps, observed over all the surface of the globe; it has not been equally folded in all its extent, but they are found in a great number of countries, and even beneath strata almost korizontal. Sometimes the folds approach 
the vertical, and are close against each other; this structure indicates that pressure has been exercised in a stronger manner than I have indicated:

"These powerful lateral thrusts of the external and solid parts of the globe appear to result from a diminution which the radius of the interior pasty or fluid nucleus has undergone during millions of ages. It may have been sufficiently great to cause the solid crust (which must always have been supported on the interior mucleus, whose volume continually diminishes) to assume the forms which we know, with a slowness equal to that of the contraction of the radius.

"To return to my experiments. At the extremities of the band of clay are pieces of wood or supports, which accompany it in its movement of contraction. The clay is thus compressed at once by its adhesion to the caoutchouc and by lateral pressure of the supports." By the influence of the caoutchouc alone, without the presence

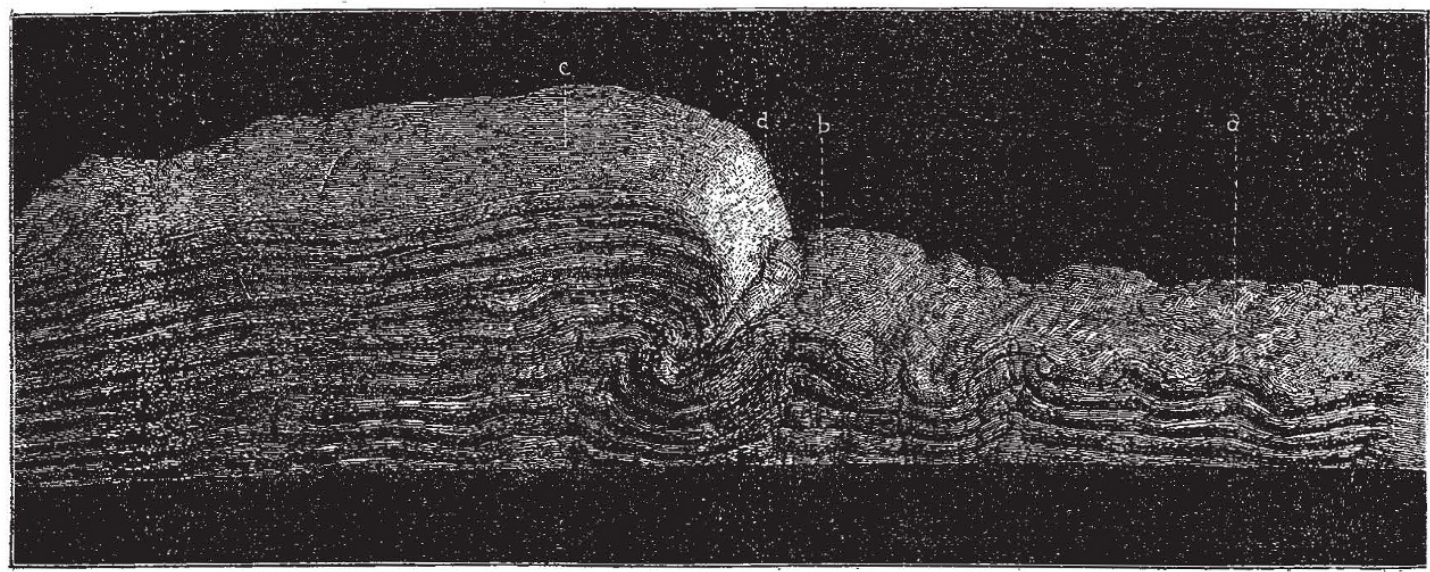

F:G. 3.

of the supports; there are formed only slight wrinkles on the surface of a sheet of clay 3 or $4 \mathrm{ctm}$. in thickness; and if the supports alone compressed the clay placed on a material which is not compressed (a very smooth oiled plate), the clay scarcely wrinkles near the centre of its surface; it increases a little in thickness and forms swellings (bourrelets) against the supports: The strata which appear to divide the masses of clay, and which are represented in the figures, are not really strata, but simply horizontal lines at the surface of the clay.

Such pressure as has been applied in these experiments produces contortions of strata which elevate the surface of the matter compressed, as well in the plane parts or plains, as in those which take the forms. of valleys, hills, or mountains. These latter bave the appearance of vaults or folds, sometimes perpendicular, sometimes warped (déjétes); the ridges are complete ${ }_{\uparrow}$

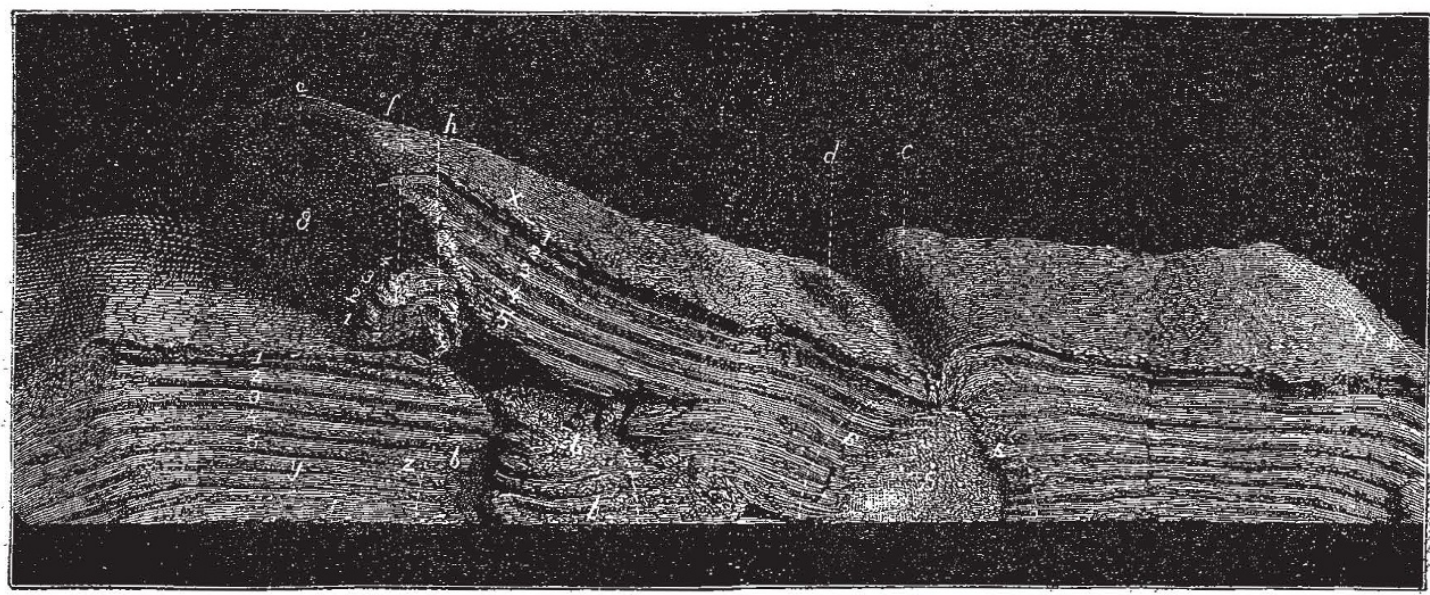

FIG. 4.

or broken at the summit by a longitudinal fracture, All these deformations are the more varied in that they: narrow below and wide above, next, another fracture, are not similar on the opposite sides of the same band of narrow above and wide below, is produced at the base of clay.

the mountain or vault: The sides of valleys are some- Most of these phenomena are seen in Fig. Iz which times almost vertical, sometimes present gentle slopes. The strata are less strongly contorted in the lower parts than in the neighbourhood of the upper surface. They are disjoined in certain parts by fissures or caverns; they are traversed by clefts or faults inclined or vertical. represents the result of an experiment made on a band of clay, whose thickness, before compression, was about $25 \mathrm{~mm}$., while after that it attained $62 \mathrm{~mm}$. at the culminating point. At $a$ is seen a vault a little broken at the summit, covering a cavern similar to that figured in 
the memoir of Sir J. Hall (Trans. R. S. E., vol. vii. 1813), and to that of the Petit Bornand in Savoy (Favre, Recherches, pl. x.) ; at $b$ is a valley open at one of its ends and almost closed at the other; at $e$ is a vault almost straight, the prolongation of which is very level; at $g, h$, and $l$ are vaults twisted and a little broken, while at $i$ is a broken fold, the curves of which are almost vertical. All these accidents of the ground recall those which have been so often observed in the Jura, the Alps, and the Appalachians.

Fig. 2 represents a band of clay whose thickness was about $40 \mathrm{~mm}$. before compression, and 65 after. We remark contortions similar to those of the preceding figure, among others a vault $a$, very exactly formed. At distances are seen vertical slices, on which the pressure appears to have acted in a particularly energetic fashion, and which may be called "zones de refoulement;" the strata are there broken in an exceptional manner, often separated from each other. One of these vaults is replaced by a single fault on the opposite side of the band of clay.

Before compression, in the band of clay in Fig. 3, were seen the two divisions which are seen there now-that in the right was $33 \mathrm{~cm}$. long, and $25 \mathrm{~mm}$. thick at $a_{2}$ and 35 at $b$; the left division was $25 \mathrm{~cm}$. long, and $65 \mathrm{~mm}$. thick. A gentle slope united the part $c$ to the part $b$. After compression, the mean height of $a b$ was 45 , and that of $c$ $75 \mathrm{~mm}$. All the layers were spread horizontally.

In this experiment I have sought to imitate the effect of crushing at the limit of a mountain and a plain. The height of the mountain $c$ has been notably increased, the five or six upper layers have advanced on the side of the plain; they encroach on it. The plain has, however, offered a resistance sufficiently great to cause the strata of the mountain to be strongly inflected at the bottom. From this struggle between the plain and the mountain, there resulted a cushion, $d$, which is the first hill at the foot of the height. It also resulted that the strata of the plain assumed an appearance of depression at contact with the mountain in ,consequence of the vault which is formed at $b$; they plunge underneath the mountain. This resembles what is often seen in the Alps at the junction of the first calcareous chain and the hills of "mollasse;" in fact, the strata of the latter rock seem to plunge under those of the neighbouring heights. In consequence of the pressure, there are formed several ranges of hills in the plain between $b$ and $a$.

"In Fig. 4 the band of clay had, before compression, a thickness of $45 \mathrm{~mm}$. ; after that the culminating point was more than ro $\mathrm{cm}$. I have here sought to represent what must happen when terrestrial pressure is exerted on horizontal strata still moist, deposited at the bottom of a sea where are two mountains already solidified. For this -purpose I placed in the caoutchouc and under the clay two bare cylinders of wood, $a$ and $b$, of labout $35 \mathrm{~mm}$. radius, at $20 \mathrm{~cm}$. from the ends of the band of clay, and at the same distance from each other. Before compression, the surface of the clay and the strata were completely horizontal. Pressure gave rise at the top of the half-cylinder, $a$, to a valley, $c$, formed by a twisting of the beds to the right, and by a little mountain, $d$, to the left. But I do not believe that it has ever been thought to assign to a valley an origin of this nature.

"On the other semi-cylinder, $b$, is produced an enormous elevation which has carried the ground to $e$, with such a repture that the left lip, $f, g$, has suffered a complete reversal by turning, as on a hinge, around the horizontal line which passes by the point $h$. It follows that the four upper strata of clay designated by the figures $1,2,3,4$, being in a normal position before compression, are, after that, so arranged as to show the succession represented by the following arrangement of figures:- $-1,2,3,4,4,3$, 2, I, I, 2, 3, 4, making the section of this formation by 2 line drawn from $x$ to $z$. If the left lip should disappear we should then have between the points $x$ and $z$ the section $1,2,3,4,5,1,2,3,4,5$. Sections analogous to these, presenting inversions in the order of strata, are known to geologists.

"The forms assumed by the clay depend on several circumstances which it is difficult to describe, such as the strength and the rate of compression, the thickness and the greater or less plasticity of the clay, \&c. Why have accidents of the upper surface of the clay, which are intimately connected with those of the interior of the mass, so small an extension that they are not even similar in the two sides of a band of clay? This small continuity is owing to causes which we can neither foresee nor appreciate. Is it not the same in nature? Why is the chain of the Alps not a true chain, but a succession of masses often oblique with respect to each other? Why, in the Jura, do we see chains which have for their prolongation plains and valleys? It is always the case that the forms and structures obtained in these experiments have an incredible resemblance to those which are found on the surface of the globe. But it must be admitted that many of the latter have not been reproduced by these artificial crushings.

"It appears probable that, by pressures more powerful and more variedly employed, we might obtain again very different structures. But I have not thought it necessary to multiply these experiments, thinking that the varied forms which have resulted show sufficiently the effects of crushing."

\section{GEORGE HENRY LEWES}

THIS is a name which has been long before the reading public of England, and the announcement of Mr. Lewes's death, on Saturday last, at the age of sixty-one years, will be received by very many with genuine regret.s This will be especially the case with those who have reached or passed middle life, for latterly $\mathrm{Mr}$. Lewes's name has come little before the public, and what work he has done appeals to a comparatively small circle. Of Mr. Lewes's many-sidedness every one knows; he commenced his career as a novelist, and ended as a physiological psychologist-perhaps in some respects no very great leap, after all; indeed the two functions may be said to be combined in that greatest of philosophical novelists, if not of novelists absolutely, "George Eliot," Mr. Lewes's widow. Science owes a good deal to Mr. Lewes; for, though he made little or no pretension to be an original investigator in physical science, he did very much by his writings to give the general public an idea of what real science is, and to help forward the good work of carrying it into every-day life. His "Physiology of Common Life" had a long and deserved popularity, and even yet, we believe, is often "asked for" at libraries and book-shops. His "Biographical History of Philosophy" is thoroughly readable and full of information, which is more than can be said of philosophical works generally. Of his "Life of Goethe," one of the very few masterly biographies, we leave it to others to speak, though he did much there to bring out the real importance of Goethe's botanical and other scientific researches. Of his latest work, "Problems of Life and Mind," we spoke at length on the appearance of the volumes that have been published; in these volumes and in one or two letters and articles contributed to our pages, Mr. Lewes was perhaps at his best as an investigator in a department of science with which we are cautious of interfering, but which has a strange fascination for many thinkers. Altogether $\mathrm{Mr}$. Lewes filled an important and many-sided place in the intellectual life of this country during his long career. It is easy to say that a man of his unusual keenness of mind might have achieved permanent greatness by concentrating his great store of energy in one 